\title{
Porosity and distribution of water in perlite from the island of Milos, Greece
}

\author{
Stephan Kaufhold ${ }^{1 *}$, Anke Reese ${ }^{2}$, Werner Schwiebacher ${ }^{3}$, Reiner Dohrmann ${ }^{1,4}$, Georg H Grathoff ${ }^{5}$, \\ Laurence N Warr ${ }^{5}$, Matthias Halisch ${ }^{6}$, Cornelia Müller ${ }^{6}$, Ulrich Schwarz-Schampera ${ }^{1}$ and Kristian Ufer ${ }^{1}$
}

\begin{abstract}
A perlite sample representative of an operating mine in Milos was investigated with respect to the type and spatial distribution of water. A set of different methods was used which finally provided a consistent view on the water at least in this perlite. Infrared spectroscopy showed the presence of different water species (molecular water and hydroxyl groups / strongly bound water). The presence of more than 0.5 mass $\%$ smectite, however, could be excluded considering the cation exchange capacity results. The dehydration measured by thermal analysis occurred over a wide range of temperatures hence confirming the infrared spectroscopical results. Both methods point to the existence of a continuous spectrum of water binding energies. The spatial distribution of water and/or pores was investigated using different methods (CT: computer tomography, FIB: scanning electron microscopy including focused ion beam technology, IRM: infrared microscopy). Computer tomography (CT) showed large macropores $(20-100 \mu \mathrm{m})$ and additionally revealed a mottled microstructure of the silicate matrix with low density areas up to a few $\mu \mathrm{m}$ in diameter. Scanning electron microscopy (FIB) confirmed the presence of $\mu \mathrm{m}$ sized pores and IRM showed the filling of these pores with water. In summary, two types of pores were found. Airfilled $20-100 \mu m$ pores and $\mu \mathrm{m}$-sized pores disseminated in the glass matrix containing at least some water. Porosity measurements indicate a total porosity of $26 \mathrm{Vol} \%, 11 \mathrm{Vol} \%$ corresponding to the $\mu \mathrm{m}$-sized pores. It remains unsolved wether the water in the $\mu \mathrm{m}$-sized pores entered after or throughout perlite formation. However, the pores are sealed and no indications of cracks were found which indicated a primary source of the water, i.e. water was probably entrapped by quenching of the lava. The water in these pores may be the main reason for the thermal expandability which results in the extraordinarily porous expanded perlite building materials.
\end{abstract}

Keywords: Perlite; Porosity; Water distribution; Volcanic glass; FIB; CT-analysis

\section{Introduction}

Perlite is a hydrous volcanic material dominated by alumosilicate glass. As an industrial material, perlite is mostly used in its expanded form, i.e. after heat treatment resulting in a light-weight macroporous product. Most of the expanded perlite is used for building construction in plasters, mortars, and tiles. Minor components of perlite are phenocrysts or microlites which formed before eruption of the magma (e.g. feldspar or biotite). Technically, the term perlite is used for glassy volcanic rock which can be thermally expanded to about 20 times of its volume (Koukouzas et al. 2000). Scientifically

\footnotetext{
* Correspondence: s.kaufhold@bgr.de

'BGR, Bundesanstalt für Geowissenschaften und Rohstoffe, Stilleweg 2, D-30655 Hannover, Germany

Full list of author information is available at the end of the article
}

the term perlite is used for hydrated volcanic glass. The most common volcanic glass is obsidian. The water content of typical obsidian is about 0.1 mass\%. Larger water contents of obsidians mostly result from postemplacement secondary hydration. Perlites, in contrast, contain up to 5 mass\% water. They are believed to form upon hydration of volcanic glass (Ross and Smith 1955). Classical perlites (round particles with an onion like appearance) (Lorenz and Gwosdz 2000) are distinguished from banded perlites (Allen 1988). The water required for perlite formation (glass hydration) is supposed to enter through small cracks present in the volcanic glass. Diffusion of water into the glass may cause the cracks or crack formation facilitates water diffusion (Marshall 1961; Friedmann et al. 1966; Denton et al. 2009). At the wall of the cracks the glass dissolves and smectite 
crystallizes as alteration proceeds (Denton et al. 2009). The typical hydration shells around the primary particles are about $20 \mu \mathrm{m}$ in size (Friedmann et al. 1966). The smectite at the walls would explain the presence of both, hydroxyls and molecular water in the perlite. Keller \& Picket (1954) detected hydroxyls as well as hydrogen bound water using infrared (IR) spectroscopy. According to Friedmann et al. (1966) both primary magmatic and meteoric water causing the post-formational hydration of the glass can be found in perlites. This water, in contrast to the hydration shell, was supposed to be located within the Al-Si-framework. The difficulty of distinguishing different types of perlite water also results from the fact that the primary water of the volcanic glass varies in both amount and composition, with variable mixtures of hydroxyls and molecular water (Stolper 1982; Eckert et al. 1988; Dobson et al. 1989; Silver et al. 1990; Pandya et al. 1992).

The water in perlites can be measured by IR spectroscopy. Dobson et al. (1989) found different binding energies which could be correlated with IR stretching vibration. The amount of water is measured e.g. considering the $3550 \mathrm{~cm}^{-1}$ vibration (e.g. (Nichols et al. 2002)). Also NIR spectroscopy can be used (Stolper 1982). Differential thermal analysis (DTA) is commonly used for distinguishing hydroxyls and molecular water in clay minerals. However, few studies use DTA for hydrated volcanic glasses. One DTA curve was published by Tazaki et al. (1992) but the almost continuous mass decrease was difficult to interpret.

Few studies about the spatial distribution of water in perlites were published. Tazaki et al. (1992) studied freshly hydrated volcanic glasses with TEM and described spherical structures containing hydroxyls and concluded that these spherical structures could be precursors to the formation of clay minerals. Wysoczanski and Tani (2006) published IR image analysis based on the $3550 \mathrm{~cm}^{-1}$ vibration. They found that the glass particles all contained some water whereas low water domains corresponded to phenocrysts. However, they could not reveal the water distribution within the glass.

The present study, therefore, was conducted to improve the understanding of the spatial distribution of water in perlites. Knowledge about the spatial distribution would improve the understanding of the thermal expansion of technically produced expanded perlite.

Both, bulk methods to characterize the binding of the water (infrared spectroscopy, IR, and differential thermal analysis combined with a mass spectrometer, DTA-MS) were used along with three different $2 \mathrm{D}$ or $3 \mathrm{D}$ methods (computer tomography, CT, infrared microscopy, IRM, and focused ion beam technology in combination with a scanning electron microscope, FIB).
The perlite investigated in the present study was from the most important European perlite mines located in Milos, Greece. Most of the European perlite is derived from the Greek islands of Milos, Kimolos, and Kos (Koukouzas et al. 2000). From the middle part of the Upper Pliocene to the late Quarternary, Milos was more or less continuously affected by extensive volcanism. The perlites are supposed to result from the youngest volcanic activity in Milos which in contrast to the older ones is supposed to result from relatively shallow magma chambers (Fytikas et al. 1986). This perlite is characterized as calc-alkaline rhyolite with commonly more than 85 mass\% glass and some phenocrysts. According to Koukouzas and Dunham (1994) different textural types can be distinguished: pumiceous perlite (light-weight and frothy features, only present in mines), hard perlite (dense and reddish and only appearing in the Kerdari Cap), and classical perlite (dense and mostly in contact with the hard and the pumiceous perlite in the mines). Much is known about the geological history of Milos and some information about compositional variation of Milos perlites and their applicability is available (Koukouzas et al. 2000) but none about the spatial distribution of the water within the perlite.

\section{Materials and methods}

The perlite investigated in the present study was collected in a running perlite mine in Milos (Greece). Three different specimens representing three different regions in the outcrop were collected. They differed with respect to their color (reddish, cream, white). However, no difference in water content or type of water (measured with DTA-MS and IR) was detected. Therefore, each of them would have been suitable for studying the spatial distribution of water of perlite of this deposit. One of the cream white particles (about $3 \mathrm{~cm}^{3}$ ) was selected for producing a polished thin section. This particle (the part not used for the production of the thin section) was further used for the investigation of the spatial distribution of water. For the computer tomography (CT) investigation a small piece $\left(\mathrm{ca} .1 \mathrm{~mm}^{3}\right.$ ) was cut off. In addition an expanded $1 \mathrm{~mm}^{3}$ sized perlite specimen (again about $1 \times 1 \times 1 \mathrm{~mm}=1 \mathrm{~mm}^{3}$ ) that was taken from an industrially produced product (thermally expanded perlite) was investigated with CT.

For the characterization of the bulk material, three particles with the different colors were ground together to represent the entire outcrop.

The methods used were selected to i) characterize the bulk material and ii) to gather information about the spatial distribution of pores and or water. The latter was thought to be difficult because of expectedly small pores and/or water domains. Therefore, apart from light microscopy, 
methods with higher resolution and different strengths were used.

\section{Bulk material characterisation}

X-ray diffraction (XRD) patterns were recorded using a PANalytical X'Pert PRO MPD $\Theta-\Theta$ diffractometer $(\mathrm{Cu}-$ $\mathrm{K} \alpha$ radiation generated at $40 \mathrm{kV}$ and $30 \mathrm{~mA}$ ), equipped with a variable divergence slit (20 $\mathrm{mm}$ irradiated length), primary and secondary soller slits, a Scientific X'Celerator detector (active length $0.59^{\circ}$ ) and a sample changer (sample diameter $28 \mathrm{~mm}$ ). The samples were investigated from $2^{\circ}$ to $85^{\circ} 2 \Theta$ with a step size of $0.0167^{\circ} 2 \Theta$ and a measuring time of $10 \mathrm{sec}$ per step. For specimen preparation, the top loading technique was used and quantification performed based on Kaufhold et al. (2010).

The chemical composition of powdered samples was determined using a PANalytical Axios. Samples were prepared by mixing with a flux material (Lithiummetaborate Spectroflux, Flux No. 100A, Alfa Aesar) and melting into glass beads. The beads were analyzed by wavelength dispersive X-ray fluorescence spectrometry (WD-XRF). To determine loss on ignition (LOI) $1000 \mathrm{mg}$ of sample material was heated to $1030^{\circ} \mathrm{C}$ for $10 \mathrm{~min}$.

For measuring mid (MIR) infrared spectra the $\mathrm{KBr}$ pellet technique (1 mg sample/200 mg KBr) was applied. Spectra were collected on a Thermo Nicolet Nexus FTIR spectrometer (MIR beam splitter: $\mathrm{KBr}$, detector DTGS TEC). The resolution was adjusted to $2 \mathrm{~cm}^{-1}$.

Thermoanalytical investigations were performed using a Netzsch 449 F3 Jupiter thermobalance equipped with a DSC/TG sample holder linked to a Netzsch QMS 403 C Aeolus mass spectrometer (MS). $100 \mathrm{mg}$ of powdered material previously equilibrated at $53 \%$ relative humidity $(\mathrm{RH})$ was heated from $25-1100^{\circ} \mathrm{C}$ with a heating rate of $10 \mathrm{~K} / \mathrm{min}$.

The cation exchange capacity (CEC) was measured using the $\mathrm{Cu}$-Triethylenetetramine method (Meier and Kahr 1999; Kaufhold and Dohrmann 2003). A sample mass of 0.3 and $0.4 \mathrm{~g}$ was used to increase the smectite detection limit up to about 0.5 mass\%.

The porosity was determined based on measuring the particle or specific density (AccuPyc 1330 of micromeritics using $\mathrm{He}$ ) and bulk or envelope density (micromeritics GeoPyc 1360 using a free-flowing, finely divided, dry powder $\left(\right.$ DryFlow $^{\circ}$ ) as the fluid medium instead of a liquid with a lower diameter limit of $50 \mu \mathrm{m})$. Different types of samples were investigated: powder, 1-2 mm particles, $>2 \mathrm{~mm}$, and after melting the sample $\left(1150^{\circ} \mathrm{C}\right.$ for 6 hours).

\section{Methods to gather spatial information}

Water can be detected by its characteristic infrared vibrations and the spatial distribution can be probed by IR-microscopy. In the present study a Thermo Nicolet
Continuum FT-IR microscope was used. A freshly broken even surface of the perlite was fixed on the $x-y$ stage. The following experimental conditions were selected: beam splitter $\mathrm{CaF}_{2}$, detector $\mathrm{MCT} / \mathrm{A}$, aperture 5, spectroscopic range of each spectrum $1000-4000 \mathrm{~cm}^{-1}$ with a resolution of $4 \mathrm{~cm}^{-1}$ and 16 scans each, and the step width was $3 \mu \mathrm{m}$. Because of the typically low intensity at large wave length the water deformation band at about $1635 \mathrm{~cm}^{-1}$ was selected to produce a 2-D plot.

The micro-computed tomography $(\mu-\mathrm{CT})$ imaging was performed with an "nanotom s 180" device, developed by GE Sensing \& Inspection Technologies and using the product line of phoenix $\mathrm{x}$-ray. This $\mathrm{CT}$ has a special high power nanofocus tube $(180 \mathrm{kV} / 15 \mathrm{~W})$ with an adjustable focal spot size down to $1 \mu \mathrm{m}$ in diameter, which enables very sharp imaging data sets. After the scanning process, the 3D data sets have been evaluated with VG Studio Max 2.0. Phase segmentation has been performed by using quantification tools, such as edge detection and phase contrast filter operations, to ensure high accuracy phase thresholding and volume determination. Afterwards, $2 \mathrm{D}$ as well as $3 \mathrm{D}$ visualization of regions of interest within the samples took place. The scanning parameters for the investigated samples were voltage $55 \mathrm{kV}$, current $80 \mu \mathrm{A}$, projections 1500 , average 7 , skip 3, timing $1000 \mathrm{~ms}$ and voxel size $1.06 \mu \mathrm{m}$.

For the high-resolution SEM focused ion beam (FIBSEM) investigation a Zeiss Auriga field equipped with a field emission cathode and extra-large charge coupled device (CCD) $80 \mathrm{~mm}^{2} \mathrm{CCD}$ detectors for energy dispersive $\mathrm{x}$-ray (EDX) analyses was used. Before starting the milling process the sample was sputtered with Pd. A "slice-and -view" procedure was run by milling $25 \mathrm{~nm}$ thick cuts in the form of a cross-section $20 \times 20 \mu \mathrm{m}$ in size. A full description of the methodology is described in Warr and Grathoff (2011).

\section{Results}

\subsection{Basic characterization of the perlite}

The representative perlite sample consisted mainly of silicate glass ("amorphous" in Figure 1). Minor components were biotite, quartz, and feldspar. The material can be characterized as peraluminous rhyolite glass with biotite, quartz, and feldspar phenocrysts. The most abundant element was $\mathrm{Si}\left(75\right.$ mass\% $\mathrm{SiO}_{2}$ ), followed by $\mathrm{Al}_{2} \mathrm{O}_{3}$ and minor amounts of the common earth and alkaline metal oxides. The chemical composition along with the LOI were determined after drying of the sample at $105^{\circ} \mathrm{C}$. Hence, externally bound water is not included in the LOI value given in Figure 1. The mineralogical composition was quantified using the XRD Rietveld technique, which confirmed the presence of more than 90 mass\% of an amorphous phase and about 5 mass\% minor crystalline components (2.6 mass\% quartz, 2.6 


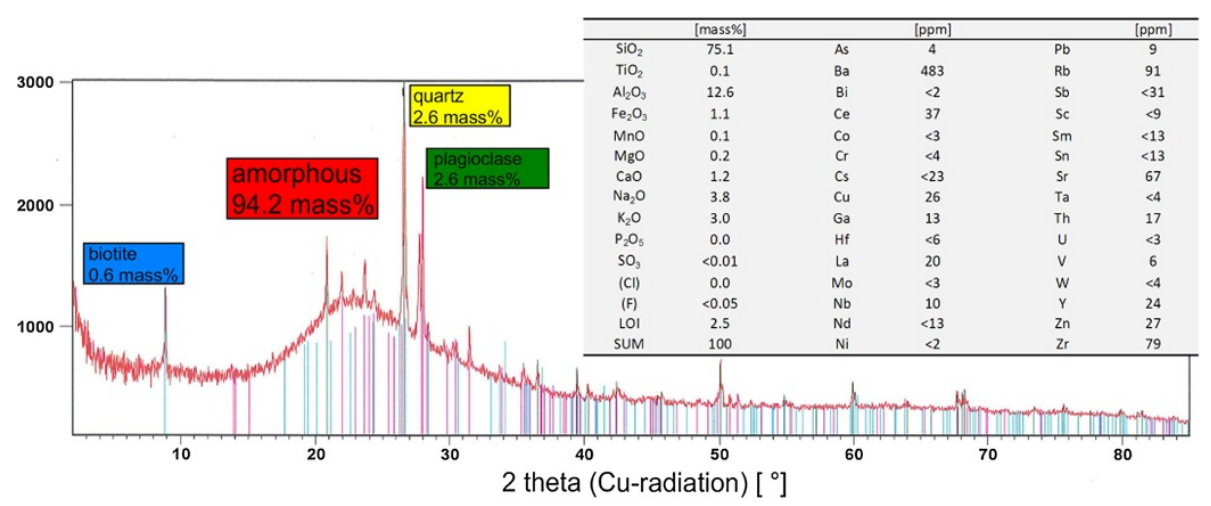

Figure 1 Mineralogical and chemical composition of the perlite sample.

mass\% feldspar, 0.6 mass\% biotite). SEM-EDX investigations and light microscopy of the polished section revealed some additional minor components, namely apatite, zircon, hornblende, and ilmenite, which were below the XRD detection limit.

The cation exchange capacity was practically $0 \mathrm{meq} /$ 100 g. In none of the 6 separate measurements any systematic reduction of the extinction at $578 \mathrm{~nm}$ was detected. The smectite content, therefore, is less than 0.5 mass\%.

The microstructure of the perlite was investigated by SEM and CT (Figure 2). The low density of the perlite results from the extensive network of pores between 20 and $100 \mu \mathrm{m}$. The significantly higher porosity of the industrially expanded perlite was imaged. The pore walls of this material are comparably thin. The section through the expanded perlite shows a hierarchy of different silicate skeletons (Figure 3, right). Mostly clusters of smaller pores are arranged in a silicate skeleton with slightly thicker walls (circle in Figure 3 ).

\subsection{Characterization of the water binding}

To investigate the binding energies of the water, thermal analysis and IR measurements were conducted. Thermal analysis showed a dehydration peak ranging from approximately $100^{\circ} \mathrm{C}$ up to $400^{\circ} \mathrm{C}$ (Figure 4) with a peak slightly below $300^{\circ} \mathrm{C}$. This peak was observed in the DSC curve - with increasing temperature with the negative values reflecting the endothermal dehydration reaction and the upward peak indicating an exothermal reaction such as recrystallization occurring at ca. $930^{\circ} \mathrm{C}$ as well as in the water mass spectrometer (MS) curve (mass 18). Other natural water containing materials such as swelling clays or even zeolites typically show much sharper dehydration peaks i.e. a water desorption within a smaller temperature range. The small DSCpeak at $573^{\circ} \mathrm{C}$ resulted from the quartz inversion. The amount of water lost from 100 to about $600^{\circ} \mathrm{C}$ was 2.7 mass\% (read from the TG curves, not shown here) which is in reasonable agreement with the LOI data shown before.

The MIR spectrum after drying for $24 \mathrm{~h}$ at $150^{\circ} \mathrm{C}$ in vacuum still showed the presence of molecular water $\left(1630 \mathrm{~cm}^{-1}+\right.$ intensity around $\left.3400 \mathrm{~cm}^{-1}\right)$ along with the typical $\mathrm{Si}-\mathrm{O}$ and $\mathrm{Al}-\mathrm{O}-\mathrm{Si}$ vibrations resulting from the crystalline and the amorphous silicates (Figure 5). In the $\mathrm{OH}$ stretching region no distinct band could be found. Instead a broad band ranging from the typical $\mathrm{OH}$ stretching region of Al-rich clay minerals $\left( \pm 3630 \mathrm{~cm}^{-1}\right)$ to the region being typical of water adsorbed in micropores
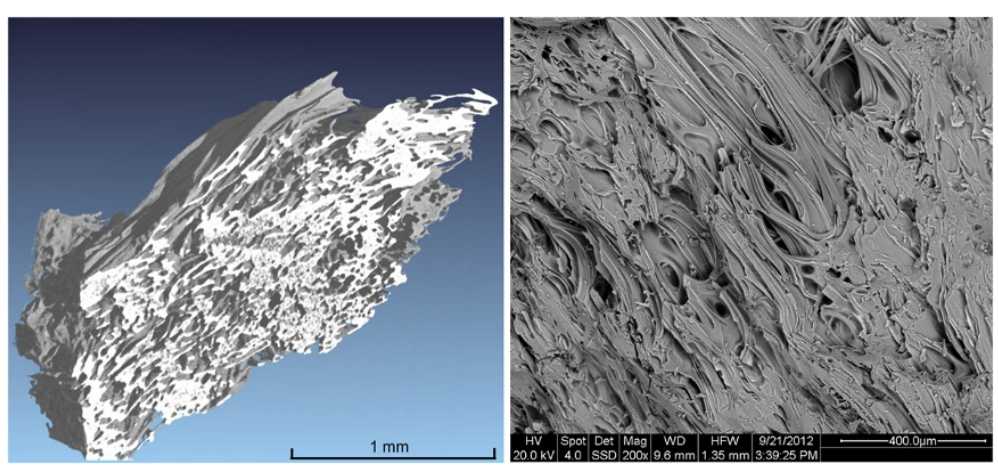

Figure 2 Microstructure of raw perlite visualized by CT (left) and SEM (right). 

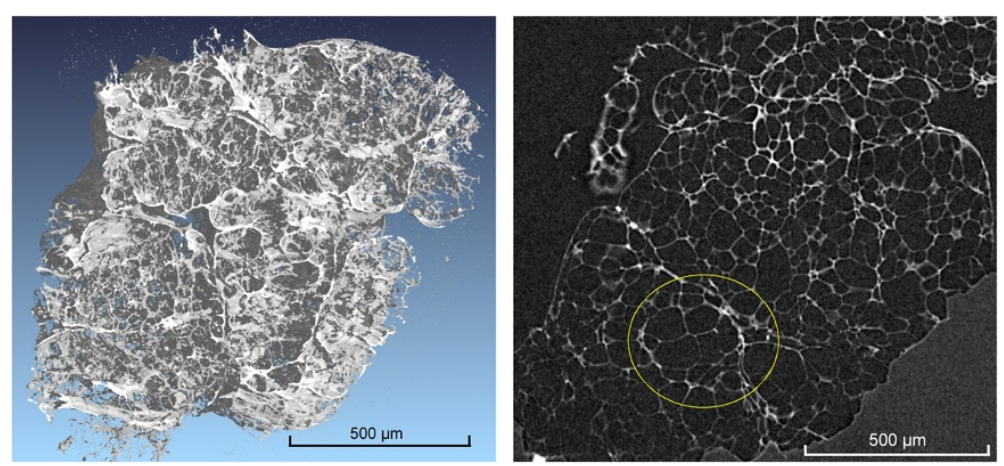

Figure 3 Microstructural investigation of expanded perlite by CT (left pseudo 3D image, right 2D cross-section). The circle shows that small pores with thinner walls are included in spherical structures with somewhat larger walls.

(e.g. $3410 \mathrm{~cm}^{-1}$ in the case of ferrihydrite) was observed. The DTA curve could be interpreted in a way that the water inside the silicate glass could not leave at lower temperatures, which would shift the dehydration towards larger temperatures. However, such kinetic effects do not affect the IR spectrum. Therefore, both, the IR and DSC results, indicate the presence of a continuous range of differently bound water molecules ranging from structural $\mathrm{OH}$ groups similar to those present in clay mineral structures to free molecular water. The bands at larger wavenumbers (e.g. $3620 \mathrm{~cm}^{-1}$ ) can also result from water bound directly to cations (strongly bound to a surface as inner sphere complex (Bishop et al. 1994)).

\subsection{Spatial information \\ Light microscopy}

Light microscopy was performed to find fluid inclusions which cannot be detected by SEM or CT methods. Both types of perlite texture, the classical texture (Figure 6, left) and the banded type of perlite (Figure 6, right), were observed. Light microscopy also revealed an extensive network of cracks which could have been the pathway for water which hydrated the volcanic glass.

\section{Computer tomography (CT)}

CT allows investigation of the 3D structure of a sample and provides $2 \mathrm{D}$ sections. The grey values of the image shown in Figure 7 ( $1 \mu \mathrm{m}$ thick $2 \mathrm{D}$ section) correspond to the density of the investigated particles. A mottled structure was observed within the glass particles. Hence even the interior of the volcanic glass is not as homogeneous as expected. Disseminated dark spots were observed which indicated a possibly existing porosity. The diameter of these spots was $1-4 \mu \mathrm{m}$. The spots were dark because they were transparent in the $1 \mu \mathrm{m}$ section due to water or gas filling.

In addition an automatic grey scale analysis was performed. Most of the detected grey values were black (corresponding to interval 1 in the top right insert in Figure 7). The second most grey value was attributed to the volcanic glass (interval 3). However, a closer look at the interval 3 peak reveals a shoulder towards slightly lower density grey values. These could be the hydrated walls of the glass surface or otherwise represent an artifact. This grey value interval 2 was selected and the corresponding areas were marked in blue (Figure 7). These particles or areas are almost entirely located at the particle edges indicating the beginning of hydration of the outer surfaces of the glass particles.
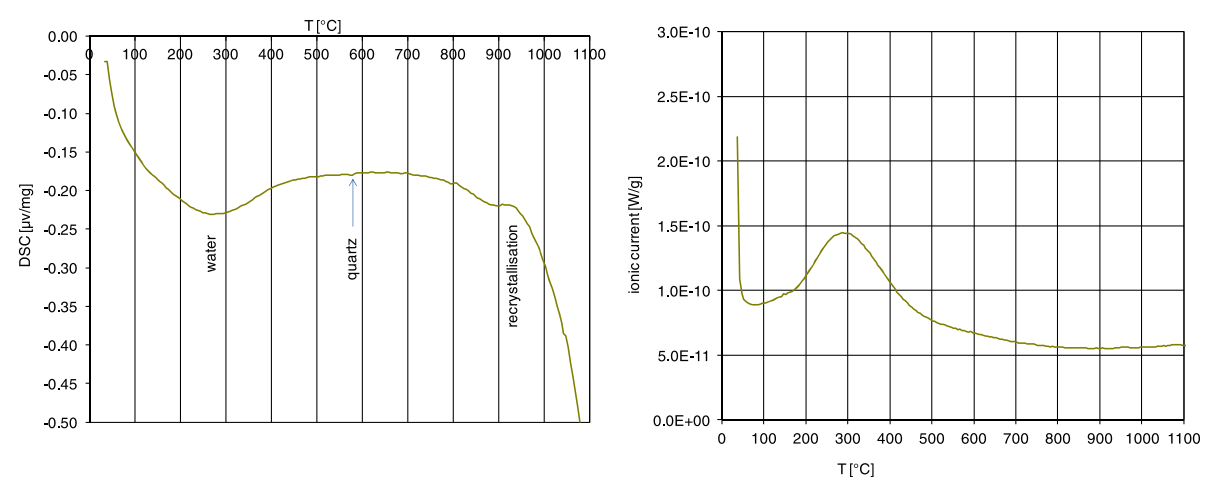

Figure 4 DSC curve (left) and $\mathrm{MS}-\mathrm{H}_{2} \mathrm{O}$ curve (right) of the perlite sample. 


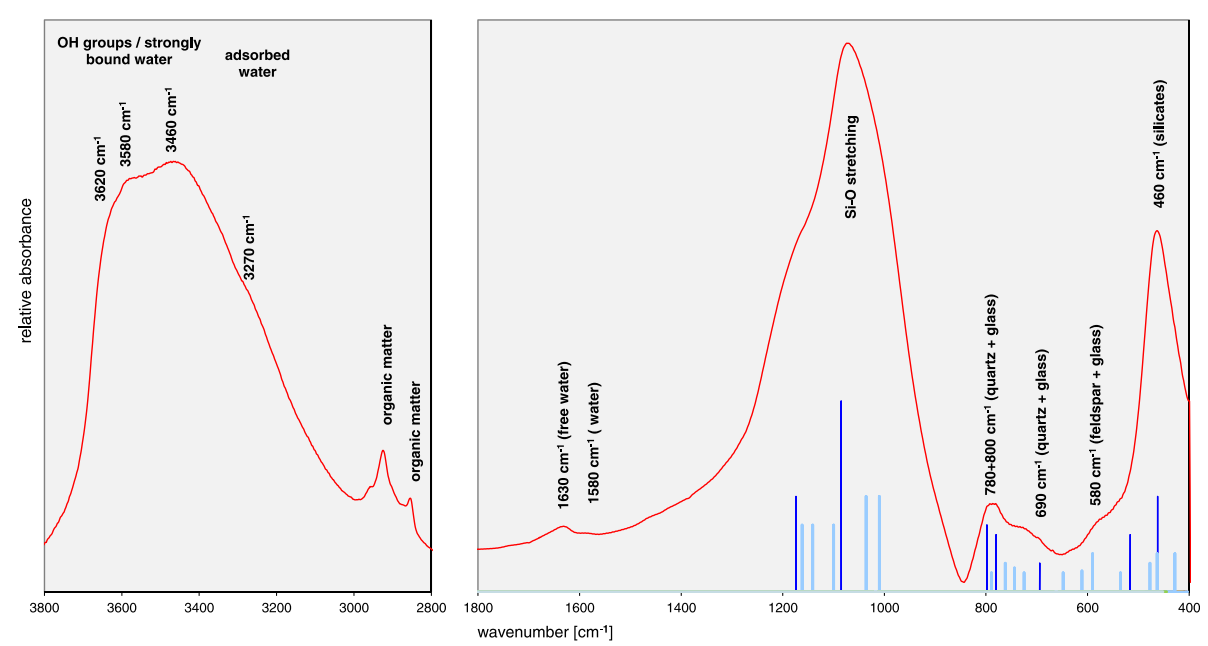

Figure 5 IR spectrum of the perlite sample (pellet dried for $24 \mathrm{~h}$ at $150^{\circ} \mathrm{C}$ in a vacuum oven).

\section{FT-IR-microscopy}

The investigated area of the even surface (unpolished) was approximately $150 \mu \mathrm{m} \times 100 \mu \mathrm{m}$ (Figure 8). Altogether more than 2000 spectra were collected across this area. The individual spectra were dominated by the $\mathrm{Si}$-O-stretching bands. Because of the reflectance mode the quality of the spectra was poor but differences in the water deformation region around $1635 \mathrm{~cm}^{-1}$ were observed. After normalization of all spectra the extinction of this band was plotted as 2-D image (Figure 8). This image proved the presence of water in several small areas with a diameter of about $5 \mu \mathrm{m}$. These domains appear circular, which is an artifact caused by the resolution of the microscope which is not sufficient to detect the shape of the water domains. Nevertheless, the IR-microscopy showed the presence of water in these small domains.

\section{FIB-SEM}

Crossbeam FIB-SEM investigations carried out in the highvacuum mode provided much clearer SEM images of the glass and of possible hydration products. In the left image of Figure 9 small sub-micron sized flakes were observed.
These could be dust but they were evenly distributed over the surface and showed a smectite like morphology (the typical rose like aggregates). In the right image of Figure 9 a coating of some parts of the surface was observed which again considering the morphology could be clay minerals. These phases could be smectites or other hydration products of the volcanic glass. However, the content of these clay minerals is much below the detection limit of the XRD and CEC method as discussed before. They can only be found on a few surfaces and hence they are not important from a statistical point of view.

The 2D polished slices and "slice-and-view reconstructions" (Figure 10) show the size and shape of two of the pores and potential alteration rims around the pore as well as minor heterogeneities in the glass (Figure 10). The back scatter electron (BSE) images revealed pores coated by higher density glass, which may be partly an artifact, based on that some of the rims contain Gallium derived from the milling processes. Using the 3D-visualisation software AVIZO Fire (www.vsg3D.com) one of the pores was investigated in more detail (Figure 10, right). Some columnar structures were observed in the pore.
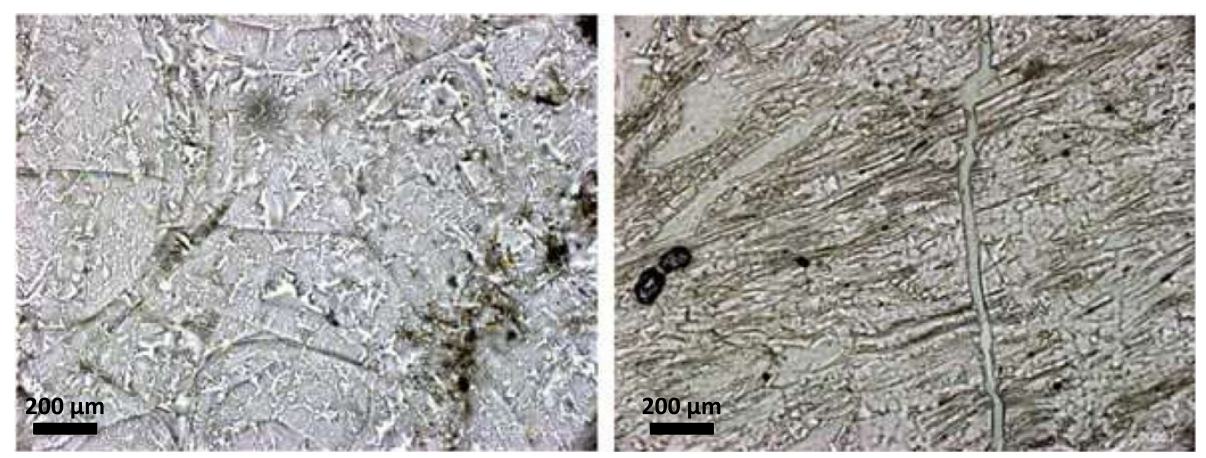

Figure 6 Light microscopical analysis of the thin section of the perlite sample. 


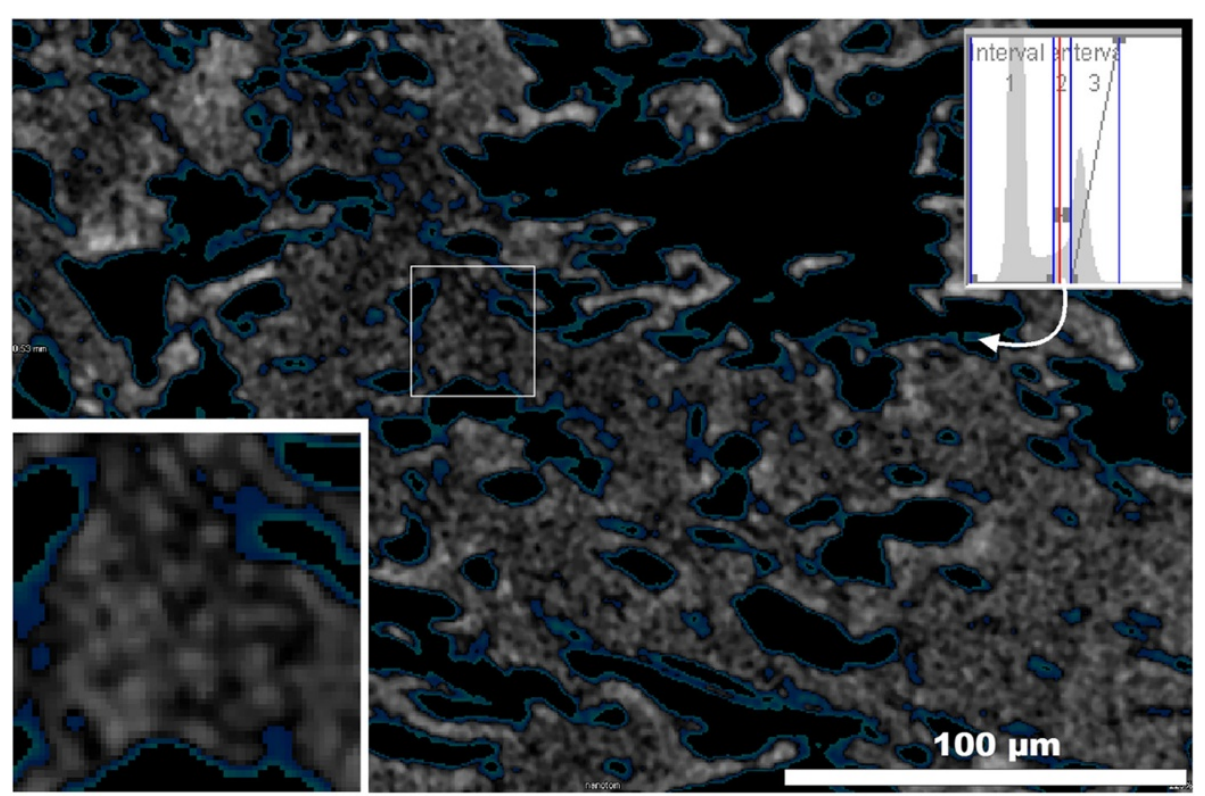

Figure 7 Grey value analysis of a CT section and magnified detail of the image. The top right insert shows the grey value distribution over the entire sample.

\section{Porosimetry}

The porosity was determined by $\mathrm{He}$ - and Dryflow ${ }^{\bullet}$-pycnometry. The density of the glass without any pores (after melting) was about $2.6 \mathrm{~g} / \mathrm{cm}^{3}$ a typical value of silicate glasses. Without extensive heat treatment and grinding the $\mu \mathrm{m}$-sized matrix porosity was thought to be intact but He could of course - only - enter the larger macropores. The specific density of this material was about $2.3 \mathrm{~g} / \mathrm{cm}^{3}$. This difference, therefore, can be explained by the existence of the $\mu \mathrm{m}$-sized matrix-porosity accounting for $11 \mathrm{Vol} \%$. The Dryflow-density of the larger grain fraction was $1.8 \mathrm{~g} / \mathrm{cm}^{3}$ which results in a total porosity of about $26 \mathrm{Vol} \%$. This value is supposed to include the macropores. The porosity of the silicate matrix is about $10 \%$.

\section{Discussion}

Infrared spectroscopy showed extinction over a wide range of wavenumbers covering both the $\mathrm{OH}$-stretching region of clay minerals as well as the spectral region typical of free water. This indicated the presence of a range of water binding forms which is in accordance with Dobson et al. (1989). As a further tool to study water binding, differential thermal analysis was applied which confirmed the IR results. The $\mathrm{MS}-\mathrm{H}_{2} \mathrm{O}$ curve (evolved gas analysis measured by mass spectrometry) showed dehydration over an unusually broad temperature range (from 100 to $400^{\circ} \mathrm{C}$ ) which was already observed by Tazaki et al. (1992). Desorption of free water is commonly observed between 100 and $200^{\circ} \mathrm{C}$ well separated from dehydroxylation $\left(500-750^{\circ} \mathrm{C}\right)$. However, no separate second peak which could be assigned to dehydroxylation was observed. Instead one broad peak was found which may correspond to both dehydration and dehydroxylation. This conclusion is supported by the IR results which also indicated the presence of a range of different water bindings, ranging from the typical hydroxyl stretching vibrations to adsorbed water. The hydroxyls do not result from smectite because the smectite content as determined by the cation exchange capacity (CEC) method was $\leq 0.5$ mass\%. This content was too low to conclude that the hydroxyls were associated to smectite. One explanation would be that the walls of an extensive pore system are covered with hydroxyls or at least strongly bound water which in terms of binding energy are similar to clay mineral hydroxlys but in this case only cover the very surface.

Using the thermal gravimetry curve the water liberated from the perlite could be quantified (about 2.7 mass\%). This value was slightly larger than the loss on ignition (LOI $=2.5$ mass\%) which can be explained by the fact that the sample was stored at $53 \%$ r.H. prior to thermal analysis but dried at $60^{\circ} \mathrm{C}$ prior to LOI determination. Both values, however, are in good agreement.

The aim of the present study was to investigate the spatial distribution of the water. Different methods were used, each with specific strengths and weaknesses. Computer tomography provided a 3D image of density distributions. Using image analysis a grey value distribution was calculated which showed slightly darker surfaces of the particles which indicated areas of lower density, probably a beginning hydration. As explained above, the smectite content was too low to explain this observation. 


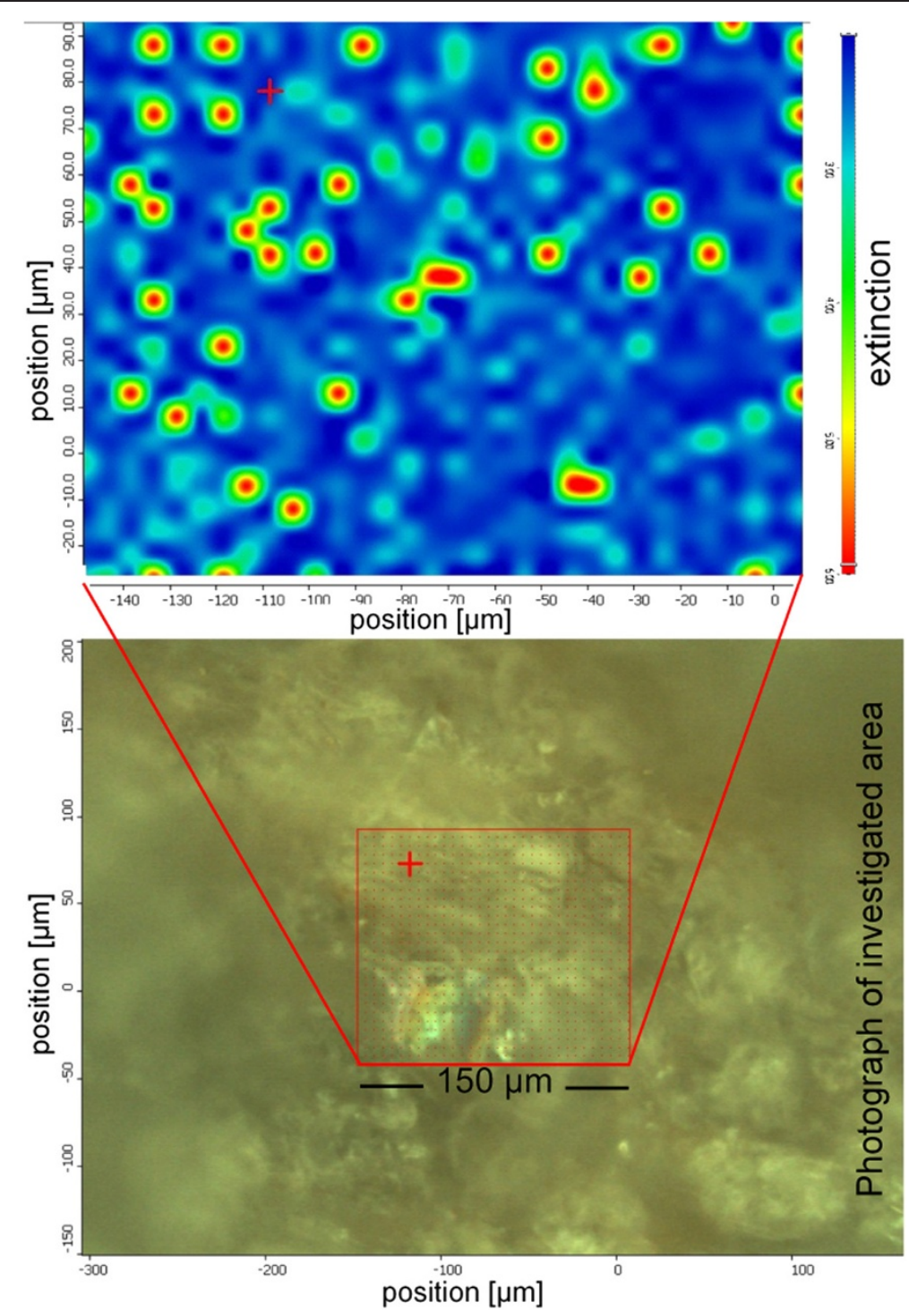

Figure 8 Infrared microscopy of the perlite sample. Top: 2-D plot of the extinction of the $1635 \mathrm{~cm}^{-1}$ vibration of water, bottom: photograph of the perlite surface and investigated area.
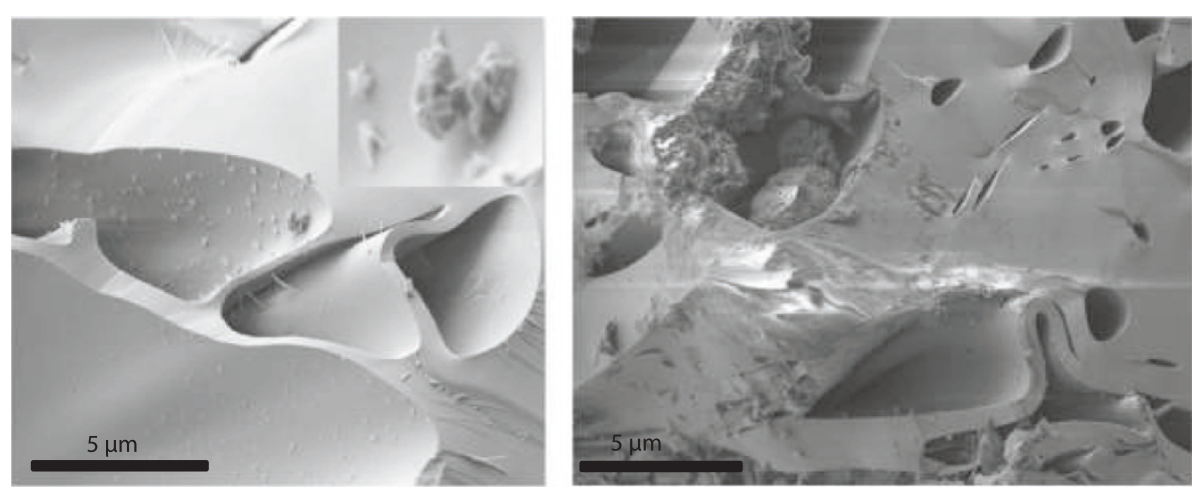

Figure 9 SEM (high-vacuum) image of some pores of the perlite showing indications for hydration products. 

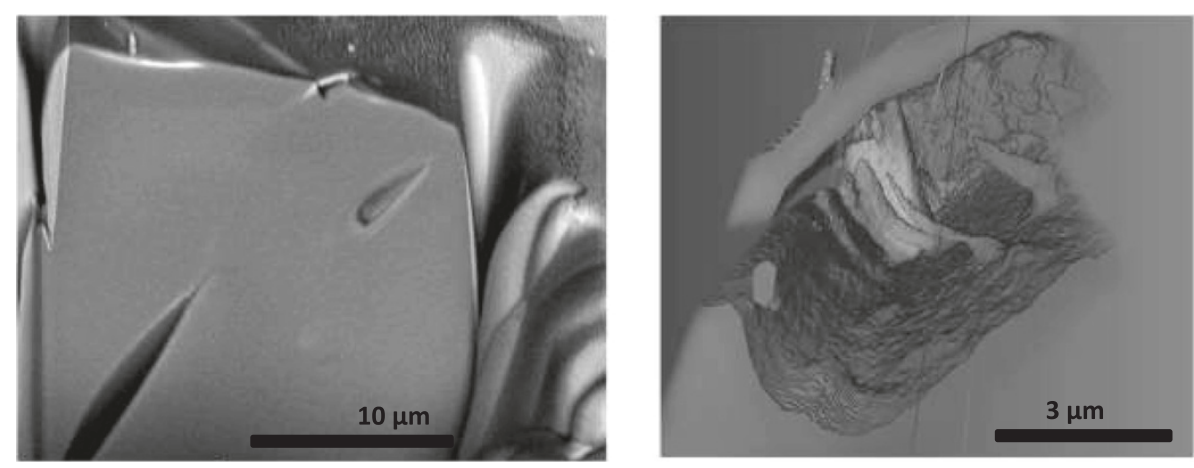

Figure 10 SEM (high vacuum) image of FIB slice 107 (left) and AVIZO Fire-visualization (3D slice and view reconstruction) of one of the pores based on the FIB measurements (right, image width $10 \mu \mathrm{m}$ ).

It could be explained by a small hydration layer but further interpretations would be speculative. The most interesting CT-results were found by considering $1 \mu \mathrm{m}$ slices (2D assessment of the $3 \mathrm{D}$ data set). Of course the large pores which were observed with light microscopy were well resolved. In addition, however, the massive glass particles appeared uneven. Dark spots close to the resolution of the method were observed all over the glass particles. Analytical artifacts were excluded and the hypothesis was that these areas could be pores. To further investigate this assumption high resolution scanning electron microscopy in combination with the focused ion beam technology allowing 3D analysis was used. This method confirmed the presence of pores in the $\mu \mathrm{m}$ range and hence supported the view that the density heterogeneity measured by CT corresponded to a system of pores. FIB-SEM proved that the pores are closed and isolated. Neither CT nor FIB were suitable to determine eventual pore filling. Therefore, IR microscopy was used. The extinction at $1635 \mathrm{~cm}^{-1}$ over a $150 \times 110 \mu \mathrm{m}$ area showed spots indicating water. The shape of these spots was an artifact because of the maximum resolution of method. However, IR microscopy proved the presence of water in small domains. At first sight these domains were considered to be analytical artifacts. However, the size and distribution of these domains fits well with the pores found by
CT and FIB. Therefore, these domains are supposed to correspond to the pores observed by CT and FIB and, moreover, identified at least a part of the filling of the pores. To show that the three methods probably identified the same pores all results were plotted in one figure (to be able to compare the scale; Figure 11).

The total porosity was $26 \mathrm{Vol} \%$ and the $\mu \mathrm{m}$-sized matrix-porosity accounted for 11 Vol\%. IR microscopy showed that the pores are at least partially filled with water. A 3D-FIB visualization of one pore showed columnar structures in the pore. These could be precipitations or newly formed phases. Further discussion about them would be highly speculative.

Most of the perlites are supposed to have formed upon post-emplacement hydration. The $\mu \mathrm{m}$-sized finely distributed pores identified in the present study, however, are ubipresent in the volcanic glass and the pores are not supposed to be connected. The pores observed are all closed. One option to explain the abundance of this water is that it was trapped when the magma was quickly cooled. This had to be investigated further, e.g. using isotope methods.

\section{Summary and conclusions}

Perlites are believed to form upon post-formational hydration often leading to smectite formation. The presence of
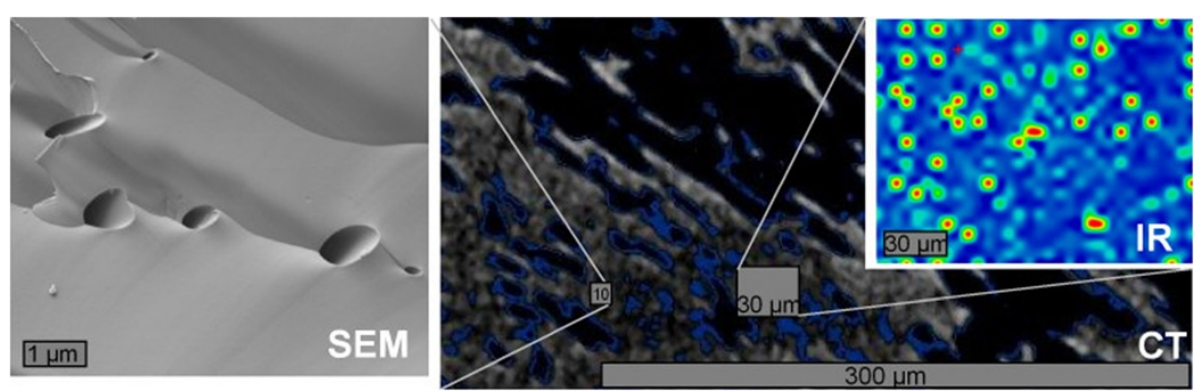

Figure 11 Concluding figure showing the mottled like microstructure revealed by $\mathrm{CT}$, the filling of pores with water (IR), and the presence of small pores detected by the SEM (FIB). 
smectite in the investigated sample, however, can be excluded. CEC measurements with high sample masses are accurate enough to prove that less than 0.5 mass\% smectite was present. Infrared spectroscopy and thermal analysis showed the presence of a continuous range of water binding, ranging from hydroxyls/strongly bound water to molecular water. Using CT and FIB an extensive pore system of closed pores was found with pore diameters in the range of $1-5 \mu \mathrm{m}$. In the same range, infrared microscopy revealed domains with significant extinction in the water deformation region. Because of similar size and distribution these signals were believed to represent the filling of the pores. According to the consistent picture gained from applying a set of different methods, the glass particles of at least the investigated material contain appreciable small water filled pores. It remains unsolved wether the water in these pores entered after or throughout the emplacement. However, the pores are sealed and no indications of cracks were found which indicates a primary source of the water, i.e. water was probably entrapped by quenching of the lava. The water in these pores may be important for the possible formation of clay minerals out of perlites and may have implications for the formation of bentonites in Milos. The water in the $\mu \mathrm{m}$-sized pores may be the main reason for the thermal expandability of this perlite.

\section{Competing interests}

The authors declare that they have no competing interests.

\begin{abstract}
Authors' contributions
SK was the supervisor of the study and wrote most of the text, AR - as bachelor student - did a lot of analytical work in the lab and the literature study, WS provided samples, access to the pit and the scientific question, $\mathrm{RD}$ took care about the smectite content determination and revised the manuscript, GG and LW performed the FIB measurements and the 3-D segmentation of the SEM data, CM performed the $\mu-C T$ measurements which were further processed by MH, US-S did the light-microscopical analysis, and KU calculated the quantitativemineralogical analysis based on XRD Rietveld. All authors read and approved the final manuscript.
\end{abstract}

\begin{abstract}
Author details
'BGR, Bundesanstalt für Geowissenschaften und Rohstoffe, Stilleweg 2, D-30655 Hannover, Germany. ${ }^{2}$ Georg-August-University Göttingen, Geowissenschaften und Geographie, Goldschmidtstr. 3, 37077 Göttingen, Germany. 'Knauf, Knauf Aquapanel GmbH, Kipperstraße 19, 44147 Dortmund, Germany. ${ }^{4}$ LBEG, Landesamt für Bergbau, Energie und Geologie, Stilleweg 2, D-30655 Hannover, Germany. ${ }^{5}$ Ernst-Moritz-Arndt Universität Greifswald, Institute für Geographie and Geologyie, Friedrich-Ludwig-Jahn-Str. 17a, D-17487 Greifswald, Germany. ${ }^{6}$ LIAG, Leibniz-Institut für Angewandte Geophysik, Stilleweg 2, D-30655 Hannover, Germany.
\end{abstract}

Received: 1 October 2014 Accepted: 6 October 2014 Published: 12 October 2014

\section{References}

Allen RL (1988) False pyroclastic textures in altered silicic lavas, with implications for volcanic associated mineralization. Econ Geol 83:1424-1446

Bishop JL, Pieters CM, Edwards JO (1994) Infrared spectroscopic analyses on the nature of water in montmorillonite. Clay Clay Miner 42(6):702-716

Denton JS, Tuffen H, Gilbert JS, Olding N (2009) The hydration and alteration of perlite and rhyolite. J Geol Soc Lond 166:895-904
Dobson PF, Epstein S, Stolper EM (1989) Hydrogen isotope fractionation between coexisting vapor and silicate glasses and melts at low pressure. Geochim Cosmochim Acta 53:2723-2730

Eckert H, Yesinowski JP, Silver LA, Stolper EM (1988) Water in silicate glasses: quantitation and structural studies by ${ }^{1} \mathrm{H}$ solid echo and MAS-NMR methods. J Phys Chem 92:2055-2064

Friedmann I, Smith RL, Long WD (1966) Hydration of natural glass and formation of perlite. Geol Soc Am Bull 77:323-328

Fytikas M, Innocenti F, Kolios N, Manetti P, Mazzouli R, Poli G, Rita F, Villai L (1986) Volcanology and petrology of volcanic products from the island of Milos and neighbouring islets. J Volcanol Geotherm Res 28:297-317

Kaufhold S, Dohrmann R (2003) Beyond the Methylene Blue method: determination of the smectite content using the Cu-triene method. Z Angew Geol 49(2):13-18

Kaufhold S, Ufer K, Kaufhold A, Stucki J, Anastácio A, Jahn R, Dohrmann R (2010) Quantification of allophane clay from Ecuador. Clay Clay Miner 58(5):707-716

Keller WD, Picket EE (1954) Hydroxyl and water in perlite from superior, Arizona. Am J Sci 252:87-98

Koukouzas N, Dunham A (1994) Genesis of a Volcanic Industrial Rock. Trachilas perlite deposit, Milos island, Greece

Koukouzas NK, Dunham AC, Scott PW (2000) Suitability of Greek perlite for industrial applications. Appl Earth Sci: Trans Inst Min Metall B 109:105-111

Lorenz W, Gwosdz W (2000) Bewertungskriterien für Industrieminerale, Steine und Erden, Teil 4: Vulkanische Gesteine und Leichtzuschläge, Bims, Bimsasche, andere vulkanische Aschen und Schlacken, Tuffgesteine, Perlit, Basalt, andere vulkanische Gesteine. Geol Jb (Reihe H7):3-111

Marshall RR (1961) Devitrification of natural glass. Geol Soc Am Bull 72:1493-1520 Meier LP, Kahr G (1999) Determination of the cation exchange capacity (CEC) of clay minerals using the complexes of Copper (II) ion with Triethylenetetramine and Tretraethylenepentamine. Clay Clay Miner 47:386-388

Nichols ARL, Carroll MR, Höskuldsson A (2002) Is the Iceland hot spot also wet? Evidence from the water contents of undegassed submarine and subglacial pillow basalts. Earth Planet Sci Lett 202:77-87

Pandya N, Muenow DW, Sharma SK (1992) The effect of bulk composition on the speciation of water in submarine volcanic glasses. Geochim Cosmochim Acta 56:1875-1883

Ross CS, Smith RL (1955) Water and other volatiles in volcanic glasses. Am Mineral 40:1071-1089

Silver LA, Lhinger PD, Stolper E (1990) The influence of bulk composition on the speciation of water in silicate glasses. Contrib Mineral Petrol 104:142-162

Stolper E (1982) Water in silicate glasses: an infrared spectroscopic study. Contrib Mineral Petrol 81:1-17

Tazaki K, Tiba T, Aratani M, Miyachi M (1992) Structural water in volcanic glass. Clay Clay Miner 40:122-127

Warr LN, Grathoff G (2011) Geoscientific applications of particle detection and imaging techniques with special focus on the monitoring clay mineral reactions. In: Grupen C, Buvat I (eds) Handbook of Particle Detection. Springer, ISBN 978-3-642-13270-4, 667 - 685

Wysoczanski R, Tani K (2006) Spectroscopic FTIR imaging of water species in silicic volcanic glasses and melt inclusions: An example from the Izu-Bonin arc. J Volcanol Geotherm Res 156:302-314

doi:10.1186/2193-1801-3-598

Cite this article as: Kaufhold et al:: Porosity and distribution of water in perlite from the island of Milos, Greece. SpringerPlus 2014 3:598.

\section{Submit your manuscript to a SpringerOpen ${ }^{\odot}$ journal and benefit from:}

- Convenient online submission

Rigorous peer review

- Immediate publication on acceptance

- Open access: articles freely available online

- High visibility within the field

- Retaining the copyright to your article

Submit your next manuscript at $\gg$ springeropen.com 